\title{
A INTERIORIDADE E A QUESTÃO DO SOBERANO BEM EM PASCAL
}

\author{
Rodrigo Hayasi Pinto*
}

\begin{abstract}
Resumo: O objetivo que permeará a presente discussão está vinculado à tentativa de elucidar em que consiste a questão do autoconhecimento em Blaise Pascal. A nosso ver, essa questão está estritamente relacionada com a temática da busca pelo soberano bem, presente nos "Pensées", mais especificamente nos fragmentos relacionados ao "Divertissement". Nesses fragmentos o pensador francês trabalha com a idéia da miséria presente no homem, sob a forma de uma espécie de vazio interior. A natureza do homem, sendo esvaziada de todo e qualquer significado, impele-o a buscar nas distrações e ocupações um modo de tornar-se feliz. Nesse sentido, conhecer-se a si mesmo, segundo Pascal, equivale a reconhecer sua própria miséria no contexto do fenômeno do divertimento. Por outro lado, pretendemos fazer uma comparação entre o pensamento de Pascal e o de Santo Agostinho, no que tange à temática da interioridade e da busca pelo soberano bem, para mostrar como a reflexão antropológica do autor jansenista acerca desses temas ultrapassa o pensamento do bispo de Hipona.
\end{abstract}

Palavras-chave: Antropologia, moral, autoconhecimento, subjetividade, angústia.

\section{Introdução}

Uma das características do pensamento de Blaise Pascal é certa influência sofrida pela doutrina de Santo Agostinho. O jansenismo, corrente do catolicismo a que Pascal aderiu, é profundamente influenciado pelo pensamento agostiniano, até o ponto de um dos principais comentadores da filosofia de Pascal, Jean Laporte, afirmar que Pascal, quando se referia aos jansenistas nas cartas e nos "Escritos sobre a Graça", preferia chamá-los de "discípulos de Santo Agostinho" e jamais usava o termo "jansenista".

O que apoiaria esta conjectura, é o termo Jansenistas que Pascal não emprega jamais, a não ser colocando-o na boca de um adversário (ver, por exemplo, o fr. 929) ou até mesmo de um indiferente (ver as Provinciais): quando ele fala por sua conta, nas suas cartas ou nos Escritos sobre a Graça, ele emprega a expressão que é para Arnauld e os outros escritores de Port-Royal a expressão consagrada: discípulos de Santo Agostinho (Laporte 6, p.165).

Uma das principais obras que tentam uma aproximação entre o pensador francês e o bispo de Hipona é "Pascal e Santo Agostinho" de Philippe Sellier. No

\footnotetext{
* Professor da Pontifícia Universidade Católica do Paraná
} 
entanto, embora Sellier pretenda fazer uma série de relações das duas filosofias nos mais diferentes níveis, epistemológico, moral e religioso, mostrando pontos de igualdade entre ambas, já no início da obra ele faz uma afirmação curiosa. Segundo esse comentador, Pascal "ultrapassou o bispo de Hipona na pintura que ele fez da inconstância psicológica do ser humano. Não somente o homem não passa de um joguete em meio aos elementos, mas ele também é fluente, mutável” (Sellier 11, p.33).

A temática da presente discussão tem como objetivo principal mostrar a peculiaridade da interpretação do homem em Pascal dentro do contexto da antropologia cristã, mais especificamente com relação àquela defendida por Agostinho. Dentro desse quadro, pretendemos mostrar em que sentido Sellier estava certo, ao apontar que o pensamento de Pascal "ultrapassa" aquele de Santo Agostinho.

Desse modo, não se trata apenas de apresentar as semelhanças e aproximações entre os dois autores, tal como fez Sellier de maneira magistral em sua obra, nossa intenção consiste, sobretudo, em mostrar a originalidade do pensador jansenista diante da doutrina agostiniana no que tange à temática da inconstância do homem e do autoconhecimento. Acima de tudo, nossa análise consiste em mostrar de que modo conceitos como a noção de interioridade e a temática relacionada à busca do soberano bem, ainda que no pensamento pascaliano continuem a estar relacionados com o âmbito do autoconhecimento, são transformados em noções mais vinculadas à miséria e ao desejo de distração presentes no fenômeno do divertimento.

\section{Interioridade e soberano bem em Agostinho}

Qual a necessidade do homem encontrar o repouso e o soberano bem da perspectiva do pensamento agostiniano? No início das "Confissões", Agostinho nos diz que o objetivo de todo ser humano é buscar o repouso, e mais do que isso, esse repouso somente poderá ser obtido quando o situarmos em Deus. "Nos criastes para vós e o nosso coração vive inquieto, enquanto não repousa em vós" (Agostinho 1, p.37). Desse modo, trata-se de compreender que a natureza do homem deve ser representada essencialmente por uma eterna inclinação na direção de um bem absoluto e transcendente, pois somente tal bem poderá saciar sua inquietude.

Ora, segundo Agostinho, a vontade decaída não é capaz de encontrar no estado de corrupção nada que satisfaça esse desejo, assim o substitui por qualquer objeto que lhe dê a ilusão de representar a paz tão desejada. Nesse sentido, para o bispo de Hipona, 
há uma gama infindável de coisas capazes de nos levar à inquietação trazendo-nos o desejo da conquista. Cargos, coisas materiais, reconhecimento, realizações pessoais, enfim somos tragados por um desejo perpétuo de encontrar em cada uma dessas coisas um bem absoluto, capaz de nos trazer a felicidade. No entanto, infelizmente, a concretização desse ímpeto nunca se verifica, pois a cada nova conquista somos constantemente atormentados a buscar num novo modo de satisfação algo que aplaque nosso desejo de felicidade.

Desse modo, embora cada ser humano idealize uma espécie diferente de felicidade, tendo em vista a conquista de diferentes bens, a vontade que o impulsiona em direção a ela é um comportamento comum, que se encontra disseminado de forma generalizada. Segundo Agostinho, aquilo que impele o indivíduo a buscar o soberano bem é um peso que move nossa vontade intermitentemente: o amor.

Em cada alma, como em cada corpo, há um peso que a arrebata incessantemente e move-a continuamente a buscar o lugar natural de seu repouso; isto é o amor. Meu peso, diz Agostinho, é meu amor: pondus meum amor meus; eo feror quocumque feror" (...) Se o amor é o motor íntimo da vontade, e se a vontade caracteriza o homem, podese dizer que o homem é essencialmente movido por seu amor (Gilson 4, p.256-257).

Essa ideia do peso Agostinho tomará da física grega, notadamente a de Aristóteles. Segundo a física aristotélica, cada corpo é arrebatado por certo peso natural, o qual aponta para um determinado lugar, que representa o repouso. Assim, essa tendência leva o fogo, quando deixado a si mesmo, a subir, e uma pedra a cair, quando abandonada por quem a segura. De maneira semelhante, Agostinho conceberá o homem e suas inclinações. Somente que, nesse caso, a caracterização do peso recebe um qualificativo afetivo, é chamado de "amor" com a intenção de mostrar a sua estreita relação com a vontade humana.

Assim, somos levados a amar de modo incondicionado, ou seja, como se trata de uma inclinação natural de que somos todos possuidores, não temos como nos furtar a essa lei. O desejo, responsável pela dinâmica de todas as nossas ações, se manifestará de maneira variada, visto que o desejo de cada homem assumirá uma configuração diferente na medida em que cada um visar diferentes maneiras de tornar-se feliz. Ironicamente os próprios crimes e assassinatos são também um sintoma dessa liberdade impensada proporcionada pelo amor, já que é possível "amar" o próprio mal ao invés do bem. 
Crimes, adultérios, homicídios, luxúrias é o amor que causa tudo isso, bem como os atos de caridade pura ou de heroísmo. Tanto no bem como no mal sua fecundidade é infatigável, e é, para o homem que ele conduz, uma fonte inesgotável de movimento (Gilson 4, p. 258).

Por outro lado, segundo Agostinho, o único objeto capaz de nos satisfazer plenamente é Deus. Com efeito, Deus por possuir uma natureza imutável, incorruptível e eterna é o único ser por excelência, capaz de encarnar a idéia de um bem absoluto, ao contrário dos bens terrenos. Mas, como adentrar no caminho que leva a Deus, na medida em que o mundo habitado por nós é aquele da corrupção, do movimento e da inconstância, e a prova disso é que a busca pelo referencial moral produz uma variedade de comportamentos diversos?

$\mathrm{Na}$ perspectiva agostiniana, o verdadeiro caminho para chegarmos ao verdadeiro repouso, que é Deus, não está relacionado aos bens exteriores e corruptíveis, mas deve passar pela "interioridade". Na obra "O Livre-Arbítrio", Agostinho nos mostra como é possível aceder a um conhecimento da existência do próprio Deus seguindo uma via interiorizante e racional. Para o bispo de Hipona, o caminho que leva a Deus deve passar pela interioridade, ou seja, por uma análise da alma racional com o objetivo de procurar determinadas marcas, que apontarão para a existência de um ser superior.

Assim, devemos atentar para o fato de que, segundo Agostinho, não basta para provar a existência de Deus encontrar um ser que goze de atributos que simplesmente ultrapassem o homem, mas é necessário ultrapassar "algo" em nossa própria alma, que seja um indicativo da existência de Deus. "Então, não é suficiente ultrapassar o homem para alcançar tal ser, mas deve-se ultrapassar no homem algo tal que o que se encontre além dele só possa ser Deus" (Gilson 4, p.39).

Ora, há algo no homem que pode ser um indicativo da própria existência de Deus, trata-se da verdade acerca dos números. Com efeito, segundo o bispo de Hipona a compreensão do que seja a própria unidade, a qual é o fundamento da própria noção de número, não pode ser decorrente dos sentidos e nem da razão. Não pode provir dos sentidos, pois não há nenhum objeto percebido que não seja constituído por partes, em outras palavras, todo corpo, por ser divisível, pode ser concebido como tendo várias partes, e assim a noção de algo unitário escapa a nossa percepção sensível.

Ora, todo aquele que reflete sobre a verdadeira noção da unidade constata que ela não pode ser captada pelos sentidos corporais. Porque todo objeto atingido por um de nossos sentidos, seja ele qual for, não é 
constituído pela unidade, mas sim pela pluralidade que o forma. (Agostinho 2, p.102).

Também não pode provir da razão, pois embora o pensamento possa formular juízos relacionados ao aspecto quantitativo da realidade, apelando para determinadas leis relacionadas aos números, ele é incapaz de julgar essas leis. A razão não julga essas regras relacionadas aos números, mas apenas as aceita como certas e evidentes.

Com efeito, quando alguém afirma: "as coisas eternas são superiores às temporais", ou então: "sete e três são dez", ninguém diz: "isso deveria ser assim". Pelo contrário, cada um apenas constata ser assim. Ninguém corrige como se fosse algum censor, mas registra com alegria como uma descoberta (Agostinho 2, p.118).

A conclusão a que chega Agostinho é que a evidência acerca da verdade dos números não provém da racionalidade, mas tem como ponto de partida uma dimensão superior a esta. Com efeito, tal âmbito não pode ser de ordem inferior, pois se esta realidade fosse inferior, provavelmente "nossos julgamentos, longe de se regulamentarem sobre ela, julgariam a ela mesma, tal como nós julgamos os corpos" (Agostinho 2, p. 117). Ora, como isso não ocorre e, portanto, não conseguimos avaliar de maneira racional a evidência dessa verdade, ela somente pode vir de uma realidade superior à mente humana, tendo as mesmas características da natureza de tal princípio, ou seja, a eternidade e a imutabilidade. O único ser que goza dessas características é Deus.

A verdade é, pois, sem contestação superior e mais excelente do que nós, porque ela é una e ao mesmo tempo torna sábia, separadamente, cada uma de nossas mentes e as faz juízes das outras coisas todas. Jamais, porém, a mente é juiz em relação à Verdade Transcendente (Agostinho 2, p. 124).

Desse modo, a lei e a verdade, referente aos números provém de Deus. Montando uma ordem hierárquica poderíamos dizer então que o homem, no nível situacional, está localizado acima das criaturas que não são dotadas de racionalidade, mas está situado abaixo de Deus, pois o pensamento racional é norteado pela verdade transcendente e divina, que não está capacitado para compreender.

Isso significa que, em primeiro lugar, o fato de termos encontrado no interior do próprio homem uma determinada verdade responsável por apontar para uma realidade mais elevada e mais perfeita, acaba conseqüentemente por ser um indicativo da existência de um ser superior. A verdade dos números é índice da existência de Deus 
e somente pode desempenhar esse papel por que a constatamos no interior do próprio homem, tal como a marca do criador na criatura. "A partir do conhecimento de si, o homem pode chegar ao conhecimento de Deus. É preciso que o homem faça o esforço de conhecer a si mesmo, para então atingir algum conhecimento do princípio que o transcende" (Novaes 8, p.174).

Em segundo lugar, o "conhecimento de si" é o único modo de termos certa compreensão da situação de nossa existência, nos colocando de maneira ordenada na ordem dos seres que existem no universo e conquistando uma espécie de referencial antropológico. Desse modo, ao voltar-se para si mesmo, o homem é capaz de compreender hierarquicamente a sua situação dentro do cosmos, acima dos animais e abaixo de Deus.

\section{O divertimento e a fuga da interioridade em Pascal}

O filósofo francês Blaise Pascal rebate os dois pontos elencados acima, não obstante ter sido influenciado pelo pensamento agostiniano, mostrando, em primeiro lugar, a impossibilidade de se encontrar na própria racionalidade um índice da existência de Deus e, em segundo lugar apontando que não há como conferir situação antropológica ao homem dentro do cosmos por intermédio de um viés subjetivo.

Embora o filósofo jansenista seja levado a uma afirmação semelhante àquela defendida pelo bispo de Hipona, ou seja, que a verdade acerca do número (ao lado de outras noções simples como espaço, movimento e tempo, por exemplo) não possa ser apreendida pela razão, ele não conclui dessa afirmação que o número seja um indicativo da presença de uma verdade transcendente que ultrapassa o próprio homem.

A compreensão dessa noção simples, assim como dos outros princípios, longe de apontar para o ser transcendente, estaria apenas relacionada a uma dimensão intuitiva do processo cognitivo chamada por ele de "coração". Essa dimensão, em âmbito epistemológico, tornaria possível a apreensão dos princípios do conhecimento e apontaria apenas para os limites de nosso intelecto, o qual é incapaz de operar um conhecimento lógico-conceitual acerca da natureza desses fundamentos, embora os compreendamos a partir do sentimento ${ }^{1}$.

Pois o conhecimento dos princípios como, como o da existência de espaço, tempo, movimentos, números, é tão firme como nenhum dos que nos proporcionam os nossos raciocínios. E sobre esses 
conhecimentos do coração e do instinto é que a razão deve apoiar-se e basear todo o seu discurso" (Pascal 9, Pensamento 282, Grifo nosso).

Segundo Pascal, a verdade acerca do número não é índice da existência de Deus, como pensava Agostinho, pois para ele não temos como saber racionalmente se tal verdade provém efetivamente de Deus, já que há limites na própria razão que nos impedem de fazer tal afirmação. Desse modo, a pretensão de se construir uma concepção de Deus a partir de certas ideias racionais (“o Deus dos filósofos”), presente nos autores pagãos do período antigo, como os estoicos e os epicuristas, será duramente criticada por Pascal. Tal concepção, na visão do autor jansenista, além de ser insensata, não contribui em nada para a nossa salvação. Mesmo Agostinho não sendo autor pagão, é digno de nota que sua concepção do número como a marca do criador em nós é proveniente da influência de uma filosofia pagã, o neoplatonismo professado por Plotino e que, portanto, essa crítica também pode ser direcionada a ele.

Mesmo se um homem estivesse persuadido de que as proporções dos números são verdades imateriais, eternas e dependentes de uma primeira verdade em que subsistem, e que se chama Deus, eu não o julgaria muito adiantado em sua salvação. O Deus dos cristãos não consiste num Deus simplesmente autor de verdades geométricas e da ordem dos elementos ; essa é a porção dos pagãos e dos epicuristas (Pascal 9, Pensamento 556).

Por outro lado, nos fragmentos relacionados à temática do "Divertimento" (Divertissement), presentes na obra "Pensamentos", é possível perceber de maneira clara uma postura com relação ao segundo ponto. Com efeito, nesses fragmentos, a subjetividade não pode mais funcionar como referencial antropológico, consistindo em um fundamento em âmbito moral. Vejamos por quê. A reflexão pascaliana acerca do homem se inicia com uma estranha constatação:

Quando, às vezes, me pus a considerar as diversas agitações dos homens, e os perigos e castigos a que eles se expõem, na corte e na guerra, originando tantas contendas, tantas paixões, tantos cometimentos audazes, e muitas vezes funestos, descobri que toda a infelicidade dos homens vem de uma só coisa, que é não saberem ficar quietos dentro de um quarto (Pascal 9, Pensamento 139).

Os homens não sabem "ficar quietos dentro de um quarto". O que isso significa? Significa que a condição humana é marcada pela insatisfação diante da ausência de ocupações. Nesse sentido, o estado de um repouso total, sem paixões, sem 
entretenimentos, é algo contrário ao homem. Sua natureza está marcada pela constante busca de determinados entretenimentos e ocupações, que a impedem de permanecer em repouso. Mas, qual seria a causa da inquietude, ou seja, qual a razão que leva-nos a sentir verdadeira repulsa pelo repouso? Pascal, de maneira mais aprofundada, tenta descobrir a razão desse curioso efeito antropológico.

Mas quando pensei mais de perto no assunto, e quando, depois de haver encontrado a causa de todas as nossas infelicidades quis descobrir-lhes a razão, achei que há uma muito efetiva, que consiste na infelicidade natural de nossa condição fraca e mortal, e tão miserável, que nada nos pode consolar, quando nela pensamos de perto (Pascal 9, Pensamento 139, Grifo nosso).

$\mathrm{Na}$ visão pascaliana, devemos discernir entre a causa e a razão de nossos infortúnios. A "causa" da infelicidade do homem está indissoluvelmente ligada à busca por determinadas ocupações, que o mantêm sempre numa inquietude constante, mas a "razão" desse curioso efeito está muito mais relacionada ao fato de que a todo momento ele evita pensar na miséria presente na sua condição. Não é agradável pensar em si e no próprio estado presente. Ora, o estado de repouso é justamente aquele em que o homem está mais propício a pensar em si mesmo.

A noção de miséria, no caso preciso desse fragmento, está indissoluvelmente ligada à constatação de uma espécie de ausência de interioridade, que caracteriza a própria subjetividade humana. Pascal qualificará a ausência de interioridade no homem utilizando termos como "nada" e "vazio". Para ele, portanto, a verdadeira "razão" que nos leva a uma busca desenfreada por determinadas ocupações e que nos impede de permanecer em repouso é a consciência desse "vazio interior".

A constatação do nada presente na subjetividade, por meio da reflexão acerca de nossa existência, é capaz de nos levar a um determinado sentimento de angústia e tédio (o termo francês é ennui), que muitas vezes pode ser insuportável. Desse modo, somos levados a buscar as mais diferentes ocupações, como uma maneira de fugirmos da consciência de nosso próprio ser e do sentimento angustiante despertado por essa consciência. "Nada é mais insuportável ao homem do que um repouso total, sem paixões, sem negócios, sem distrações, sem atividade. Sente então seu nada, seu abandono, sua insuficiência, sua dependência, sua impotência, seu vazio" (Pascal 9, Pensamento 131). 
Alguns autores, como Vincent Carraud, apontam que uma das temáticas presentes no pensamento de Pascal é a ausência de uma subjetividade como fundamento metafísico. No capítulo quarto de seu livro, "Pascal e a Filosofia", intitulado "A Destruição da Egologia", Carraud defende a ideia de que o filósofo jansenista seria um crítico da metafísica do sujeito inaugurada por René Descartes. Noções como a de um eu substancializado seriam contrárias ao pensamento de Pascal, responsável por "criticar o ego substancial em metafísica" (Carraud 3, p.294). Segundo Carraud, o Pensamento 323 anuncia explicitamente o fracasso de uma definição real do eu:

Que é o eu? Um homem que se põe a janela para ver os passantes, se eu estiver passando, posso dizer que se pôs à janela para ver-me? Não, pois não pensa em mim em particular. Quem gosta de uma pessoa por causa de sua beleza, gostará dela? Não pois a varíola, que tirará a beleza sem matar a pessoa, fará que não goste mais; e, quando se gosta de mim por meu juízo, ou por minha memória, gosta-se de mim? Não pois posso perder essas qualidades sem me perder. Onde está, pois, esse eu, se não se encontra no corpo nem na alma? (Pascal 9, Pensamento 323).

Esse fragmento é um indicativo da impossibilidade de se apreender o eu substancialmente, tal como intenta a filosofia cartesiana. Embora a tentativa de apreensão do eu nesse fragmento esteja relacionada com a dimensão afetiva, pois se trata de gostar de mim ou de alguém, a conclusão a que se chega é a impossibilidade de termos acesso direto à substância do eu. Com efeito, podemos ter acesso apenas às qualidades relacionadas a ele. Por isso dirá Pascal, "não amamos nunca a pessoa, mas somente as qualidades". (Pascal 9, Pensamento 323). Nesse sentido, não podemos concluir acerca da natureza do eu, e tomar partido optando pelo materialismo ou pelo idealismo (não sabemos se nossa subjetividade se encontra no corpo ou na alma), talvez não possamos nem concluir por sua existência efetiva, se o termo eu for tomado no sentido de substrato capaz de receber diferentes atributos. Comentando o fragmento acima, dirá Carraud:

A substância da alma não é a alma como substância. Tudo o que essa expressão comporta precisamente de substancial desaparece (...) a alma não é o substrato de nenhuma imortalidade, puramente redutível às qualidades (perecíveis) que (não) a manifestam, ela não é princípio de nada, lugar tão inabitado pelo eu quanto o corpo; a substância, aquilo que permanece sob as qualidades sucessivas, aquilo que é permanente parece não ter mais nada de substancial (Carraud 3, p.322). 
Algo digno de nota é que nesse fragmento Pascal não utiliza o termo francês "Je" tal como Descartes em suas "Meditações": "Que suis-Je?” (Que sou eu), mas utiliza o termo "moi": "Qu'est-ce que le moi?” (traduzido comumente para o português como “Que é o eu?"). Nesse caso, o Eu é interpretado como objeto pelo autor jansenista, pois "moi" em francês é um pronome reflexivo substantivado, e não em sua função de sujeito (je - pronome pessoal). Segundo Carraud, em Pascal, a tentativa de conhecer o eu não pode ser efetuada a partir de uma "presença interior de si a si", pois nunca podemos apreendê-lo subjetivamente como uma substância espiritual capaz de sustentar diferentes qualidades. Infelizmente a tradução desse termo para o português impossibilita tal constatação ${ }^{2}$.

Assim, uma das interpretações do que seria esse vazio interior, presente no fragmento 131, seria compreendê-lo a partir daquilo que Carraud chama de “insubstancialidade do eu", relacionada com a impossibilidade de se apreender o eu em termos substanciais. Nesse sentido, essa inapreensão do eu levaria o homem a um estado de angústia. Por outro lado, segundo Pascal, não se trata apenas da incapacidade de se apreender a natureza de algo, mas se trata de modo mais forte da ausência da própria natureza como referencial.

Assim, esse nada também pode estar relacionada à ideia da falta de uma natureza, responsável por fornecer determinados referenciais antropológicos, capazes de orientar o ser humano em termos práticos e morais. Com efeito, a natureza humana, na visão pascaliana, é apenas fruto do hábito. "Que são nossos princípios naturais, senão princípios de hábitos? (...) Hábitos diferentes dão-nos princípios naturais diversos, é o que nos prova a experiência”. (Pascal 9, Pensamento 92).

O hábito atua na formação de nossa personalidade moral através da repetição de determinadas formas de comportamento e de valoração das coisas, levando-nos a acreditar que tais ações e valores são efetivamente naturais. Desse modo, ao repetir certa forma de agir e de julgar passamos a acreditar na necessidade de tais ações e juízos, mesmo que eles não sejam necessários, transformando-os em "autênticos" princípios morais, os quais podem atuar como referenciais antropológicos.

Ora, podemos constatar uma variedade de princípios de ordem moral, não obstante sejam fictícios, pois pelo hábito o homem pode "naturalizar" qualquer postura moral, transformando-a em algo natural. Dirá Pascal "não há nada no mundo que não se torne natural. Não há natural que não se perca”. (Pascal 9, Pensamento 94). Mas, nesse caso, não há referenciais permanentes e universais que nos levem a um verdadeiro 
direcionamento ético e antropológico, mas há apenas falsos princípios fabricados pelo homem, os quais podem sofrer alteração a qualquer momento. "Temem os pais que o amor natural de seus filhos se extinga. Que espécie de natureza será essa então, suscetível de extinção?” (Pascal 9, Pensamento 93). Desse modo, a ausência de uma natureza humana implica num esvaziamento de sentido do próprio homem e, consequentemente, da própria subjetividade.

Segundo Carraud, os fragmentos relacionados ao hábito e ao divertimento revelam a antropologia pascaliana, a qual consiste em falar do homem confusamente e não de modo ordenado, com o objetivo de ressaltar a miséria presente em sua natureza. A miséria do homem pode ser vislumbrada através da inconstância, presente tanto no hábito, em que constatamos a ausência de autênticos princípios de ordem moral, quanto no divertimento em que se revela a questão da ausência da própria subjetividade como referencial. Para Carraud, através do conceito de divertimento, Pascal exercita a temática do "conhece-te a ti mesmo", mas sem considerar a própria subjetividade como um ponto fixo e seguro. Nesse caso, autoconhecer-se é reconhecer a própria miséria interior, marcada pela ausência de referenciais, os quais são geradores de inconstância e confusão.

Da perspectiva pascaliana "tratar corretamente do conhecimento de si mesmo, bem falar de si, é falar confusamente. O discurso confuso e descontínuo sobre o ego é o bom discurso, pois ele é apropriado a seu objeto: conhecer-se, é conhecer sua miséria". (Carraud 3, p.292). O discurso pascaliano deve ser considerado "confuso" e "descontínuo", justamente por que tal discurso não é pontuado pela tentativa de descrever a natureza humana de maneira ordenada. Conforme veremos, Pascal descreve o homem de modo ambíguo e contraditório.

A inexistência de referenciais, em Pascal, acarreta uma interpretação da natureza humana como sendo inconstante. Com efeito, a principal consequência da ausência de uma referência interior é que a desordem, a inconstância e a descontinuidade grassam no comportamento humano em sua totalidade. Nesse sentido, não há como explicar o homem de modo contínuo e ordenado, assim como resulta impossível estabelecer uma hierarquia em que este desempenharia o lugar central. $\mathrm{O}$ discurso sobre o homem, em Pascal, será marcado pela inconstância, devido ao fato da perda de sua maior referência, o eu como substância. Assim, "a descontinuidade e a confusão do discurso sobre o eu são o sinal e o efeito de sua insubstancialidade". (Carraud 3, p.301). 
$\mathrm{Na}$ tentativa de evitar o pensamento referente ao próprio ser, marcado pela insubstancialidade e pela ausência de uma natureza como referencial antropológico, o homem tentará buscar várias maneiras de fugir a um confronto consigo mesmo. Daí nascem as várias formas de ocupação: um simples passatempo, um grande empreendimento, a pesquisa pela verdade, polêmicas na filosofia e na ciência, enfim há várias formas de distrair-nos de nossa condição vazia e sem sentido. É essa inclinação perpétua para uma espécie de "distração do ser" que o nosso filósofo chama de divertimento. $\mathrm{O}$ divertimento, portanto, cumpre uma função muito específica, a qual é justamente nos desviar de pensar em nossa própria miséria.

Por mais cheio de tristeza que um homem se encontre, se porventura conseguirmos que entre num divertimento, será feliz durante esse tempo; e o homem mais feliz, se não se estiver divertindo e ocupado com alguma paixão ou com alguma distração que impeça o tédio de se espalhar, ficará logo triste e infeliz". (Pascal 9, Pensamento 139).

No entanto o divertimento, para ser considerado como tal, nunca pode ser gratuito, nesse sentido, o homem deve ser sempre movido pela conquista de algum objetivo. Em outras palavras, todo divertimento deve sempre visar à obtenção de um determinado prêmio ou à efetivação de um resultado, assim ao nos distrairmos com qualquer entretenimento, devemos ser sempre motivados por alguma paixão. Ironicamente, imaginam os homens que com a obtenção desse prêmio conquistarão o seu lugar ao sol e, assim, atingirão o repouso e a felicidade.

Não é, portanto, só o divertimento que ele procura: um divertimento mole e sem paixão o aborrecerá. É preciso que se entusiasme e se iluda a si mesmo, imaginando que seria feliz ganhando o que não desejaria que lhe dessem a fim de não jogar, a fim de formar para si próprio um motivo de paixão e excitar com isso seu desejo, sua cólera, seu temor ante o objeto que ele mesmo criou (Pascal 9, Pensamento 139).

Assim, além do fato do homem ser impelido em direção às distrações exteriores para evitar a consciência de sua própria miséria, expressa pela insubstancialidade do eu e pela ausência de autênticos referenciais de ordem moral, o que o inclina a buscar determinado divertimento é a crença de que a ocupação que o entretém está carregada de sentido, pois há um objetivo muito importante a ser atingido por meio dela. Esse objetivo representará a ilusão de que, ao ser conquistado, tornará possível a verdadeira felicidade, pois imaginamos que sua concretização irá preencher o vazio constatado em nossa natureza. 
A partir desse momento a ilusão está completa, a imaginação nos leva a crer que a busca por determinadas conquistas, a qual é a finalidade de toda ação humana, será capaz de produzir a verdadeira felicidade e levar-nos a usufruir o verdadeiro repouso. Por isso "é preciso, pois isso lhe apraz, trabalhar o dia todo para alcançar bens reconhecidos como imaginários, e, quando o sono repara as fadigas de nossa razão, cumpre-nos levantar incontinenti, para correr atrás de fumaças". (Pascal 9, Pensamento 82.

A temática da busca do soberano bem, portanto, é uma temática tão presente no pensamento pascaliano, quanto no agostiniano. Mas, com uma grande diferença. $\mathrm{Na}$ visão do filósofo jansenista, o tema da busca pelo repouso é acrescido de uma visão mais trágica e pessimista. Em Pascal, assim como em Agostinho, o homem possui certa natureza que o predispõe para o movimento. Mas, diferentemente do Bispo de Hipona, para Pascal aquilo que nos move não é apenas o amor e o desejo pelo soberano bem, pois há um elemento mais profundo que determina o próprio desejo de agitação.

Embora a idéia orientadora seja, assim como em Agostinho, uma aspiração pela conquista de um bem (fruto do divertimento) que tornará o homem feliz, há um elemento mais sutil que comanda nossas inclinações. Trata-se do vazio interior que reside na alma humana, o qual é percebido de modo tão intenso "que nada nos pode consolar, quando nela pensamos de perto". (Pascal 9, Pensamento 139). É como se o homem fosse lançado na realização de seus maiores objetivos, por esse vazio que o expulsa constantemente das imediações da própria interioridade ${ }^{3}$.

O que quer a nossa vontade, na acepção pascaliana? Com certeza não é apenas a busca pela felicidade e pelo repouso, mas queremos acima de tudo fugir da consciência de uma natureza vazia e, ao mesmo tempo, sem sentido. Estamos a todo o momento fugindo de nós mesmos, com o objetivo de escaparmos da consciência do vazio interior que corrói nosso ser. Tendo essa meta em mente, buscamos refúgio em nossas ocupações, negócios e paixões.

Logo, o desejo por uma vida feliz não é verdadeiramente o que causa a inclinação para uma espécie de realização (nesse caso o que nos move não é apenas o "amor" a um determinado bem que simbolize a felicidade), mas é muito mais a fuga desse sentimento insuportável, relacionado à consciência de nossa miséria interior. Essa postura é muito sensata, pois desligado de suas ocupações o homem estaria a mercê desse "nada interior". É esse modelo de satisfação, baseado na fuga de si, que ironicamente, confere "significado" ao seu ser. 
Podemos dizer, portanto, que ao não ser ele mesmo, ao fugir de si, o homem constrói a sua existência evitando pensar em sua existência. "Não tendo conseguido curar a morte, a miséria, a ignorância, os homens lembraram-se, para ser felizes, de não pensar nisso tudo". (Pascal 9, Pensamento 168).

É esse pessimismo pascaliano, na temática da busca pelo soberano bem, que o afasta da doutrina agostiniana. Em Agostinho, podemos dizer que a busca pela felicidade e pela verdade representa uma inclinação natural da alma, em Pascal a temática da miséria humana contamina a própria noção de alma, impedindo-a de tornarse um referencial antropológico e provocando a inquietude e a inconstância. Nesse caso, a própria interioridade do homem revela-se esfacelada, não constituindo um caminho seguro capaz de dar acesso ao ser. Deixando de funcionar como referencial, a subjetividade deixa de ser a dimensão de acesso à verdade e a via que conduz a Deus, por isso o ser humano busca nas coisas exteriores satisfazer seu desejo.

Desse modo, em Pascal aquilo que a alma busca é acima de tudo fugir de si mesma, através do ruído e da distração, sem nunca efetivar o repouso através de uma existência pacificada e tranquila. "Não é essa vida mole e tranquila, que nos deixa tempo de pensar em nossa condição que procuramos (...) é o ruído que nos desvia de pensar na nossa condição e nos diverte”. (Pascal 9, Pensamento 139).

\section{As contrariedades e o princípio do pecado original}

No entanto, ironicamente e por uma estranha reviravolta, na filosofia pascaliana a compreensão do fenômeno da busca pelo soberano bem, presente na análise do divertimento, também nos levará à adoção de uma perspectiva teológica como modelo de interpretação do homem, do mesmo modo que em Agostinho. Nesse sentido, ambos os autores se aparentam. Embora não constatemos "marcas" do criador em nós, como aponta Santo Agostinho ao fazer referência ao número (sinal de uma verdade transcendente que ultrapassa o homem), é possível perceber outro fenômeno, que pode ser um indicativo de um princípio religioso em Pascal.

Com efeito, mesmo que constatemos a impossibilidade do repouso e da felicidade como uma realização efetiva no universo concreto do homem, pois nossa natureza reside muito mais numa eterna fuga de uma situação sem distrações ${ }^{4}$, percebemos um comportamento contraditório em relação a tal impossibilidade, somos 
movidos por um desejo que nos inclina a buscar o repouso nas diferentes ocupações, embora esse desejo seja sempre irrealizável. Nas palavras de Pascal:

Nada se detém por nós. É o estado que nos é natural e, no entanto, nenhum será mais contrário à nossa inclinação. Ardemos no desejo de encontrar uma plataforma firme e uma base última e permanente para sobre ela edificar uma torre que se erga até o infinito; porém os alicerces ruem e a terra se abre até o abismo (Pascal 9, Pensamento 72).

Como explicar essa contradição? Embora, por um lado, todos os indícios apontem para a impossibilidade de atingirmos a felicidade e o soberano bem em termos morais, por outro lado, "ardemos no desejo de encontrar uma plataforma firme". Isso significa que a temática do autoconhecimento em Pascal não passará pela interioridade, como em Agostinho, mas pelo reconhecimento de tais contrariedades. Com efeito, a postura psicológica do homem frente ao fenômeno do Divertimento é sempre ambígua. Conforme apontado linhas acima, a grande ilusão criada pelo divertimento é o fato de que todo homem o toma a sério, no sentido em que acredita que as ocupações e os passatempos que busca the trarão o autêntico repouso e a felicidade. Ora, o que efetivamente percebemos é que a atitude do homem na busca de qualquer objetivo é alheia à ideia de repouso, pois a permanência nesse estado de espírito geraria um movimento de auto-reflexão que o levaria ao tédio e ao desespero.

Segundo o pensador jansenista, o que o ser humano menos quer é a autoconsciência daquilo que é. "Procuramos o repouso combatendo alguns obstáculos; e quando estes são superados o repouso torna-se insuportável. Pois ou pensamos nas misérias presentes ou naquelas que nos ameaçam". (Pascal 9, Pensamento 139). Por que nos iludimos então? Por que não procuramos o tumulto apenas como uma espécie de distração de nosso próprio ser? Nesse ponto, a imaginação desempenhará um papel importante. Com efeito, para Pascal, o homem, na deriva do divertimento, deve sempre permanecer "imaginando que seria feliz ganhando o que não desejaria que lhe dessem a fim de não jogar, a fim de formar para si próprio um motivo de paixão". (Pascal 9, Pensamento 139).

$\mathrm{O}$ aspecto ilusório do fenômeno do divertimento diz respeito ao fato de que percebemos a possibilidade da conquista do repouso através de bens imaginários. Em outras palavras, os seres humanos não desejam naturalmente um estado pacificado, sem ocupações, pois sua natureza reside na agitação e no movimento, mas não obstante essa 
constatação eles têm necessidade de "fabricar" esse estado pela conquista de bens imaginários.

Ora, devemos nos perguntar então, porque o ser humano teria necessidade de atrelar seu comportamento a determinadas fantasias? Qual é a causa do homem imaginar o estado de repouso, já que ele efetivamente não existe em termos concretos? Aqui a religião desempenhará o papel de fornecer um princípio explicativo, que permite explicar esse curioso efeito, trata-se do princípio do pecado original.

Com efeito, no contexto do divertimento podemos perceber a relação da miséria, cuja nota mais característica é o vazio interior encontrado no homem, com a ideia de concupiscência. Segundo comentadores como Luiz Felipe Pondé, a mecânica do Divertimento está relacionada, sobretudo, com a ideia cristã da corrupção da natureza. "A alma na deriva do divertissement é a imagem interna de uma mecânica que desenha a escravidão da concupiscência" (Pondé 10, p.225).

O que aponta para o princípio do pecado original, como o único fundamento responsável por explicar o homem, são justamente as contrariedades. De maneira simbólica o mito do pecado original nos mostra que houve um momento, antes da corrupção da natureza, em que o homem residia em seu estado original, próximo de Deus. Por outro lado, a queda aponta para a perda dessa natureza e consequentemente para a perda de referenciais antropológicos, que dariam sentido ao nosso agir.

Dessa maneira, os dois movimentos contraditórios que constituem o próprio divertimento podem ser visualizados à luz de uma perspectiva cristã: a predisposição para a agitação pode ser explicada pelo fato de que o homem não reside mais em sua verdadeira natureza e não possui referenciais que lhe capacitam a orientá-lo na existência, enquanto a busca por um objetivo final, que assume o papel de ponto fixo e sentido do Divertimento, é um indicativo do desejo de retorno a essa natureza perdida.

Acreditam buscar sinceramente o repouso, e, na verdade, só buscam a agitação. Têm um instinto secreto, que os leva a procurar divertimentos e ocupações exteriores, nascido do ressentimento de suas contínuas misérias; e têm outro instinto secreto, resto da grandeza de nossa primeira natureza, que os faz conhecer que a felicidade só está, de fato, no repouso, e não no tumulto; e, desses dois instintos contrários, forma-se neles um intento confuso, que se oculta da vista no fundo da alma, e os leva a procurar o repouso pela agitação (Pascal 9, Pensamento 139). 
Dessa maneira, o princípio do pecado original é capaz de decifrar as contrariedades humanas, se configurando num verdadeiro princípio hermenêutico ${ }^{5}$. Sua função é a de traduzir os dois movimentos contrários que constituem a natureza humana, explicando-lhes o sentido. Nesse caso, o significado do próprio homem não se encontra em âmbito antropológico, mas teológico. Em outras palavras, somente poderemos entender as contrariedades humanas nos colocando em uma perspectiva religiosa, a qual mostre que cada aspecto da contrariedade, movimento-repouso, miséria-grandeza, deve ser relacionada a sujeitos diferentes, o movimento e a miséria à natureza concupiscente e a grandeza e o repouso à primeira natureza.

Conhecei, pois, soberbo, que paradoxo sois em vós mesmos. Humilhai-vos razão impotente; calai-vos natureza imbecil; aprendei que o homem ultrapassa infinitamente o homem (...) Pois, enfim, se o homem nunca tivesse sido corrompido, gozaria com segurança, em sua inocência tanto da verdade como da felicidade. E se o homem só tivesse sido corrompido, não teria qualquer ideia da verdade, ou da beatitude (...) somos incapazes de ignorar em absoluto e de saber com certeza, de tal maneira é manifesto que estivemos num grau de perfeição de que infelizmente caímos (Pascal 9, Pensamento 434).

Se, para o pensador jansenista, "o homem ultrapassa infinitamente o homem", é porque o verdadeiro sentido da antropologia encontra-se na teologia. A idéia de uma sobrenatureza é a responsável por conferir situação ontológica ao homem, justamente por que o leva a compreender a natureza de suas contradições. Mas aqui, não estaríamos próximos ao pensamento do Bispo de Hipona? Afinal de contas é lícito concluir que tanto na antropologia pascaliana, quanto na agostiniana, nos deparamos com a presença de certos elementos imanentes que apontam para uma realidade de ordem teológica, a noção de número em Agostinho e as contrariedades humanas em Pascal.

Mas, mesmo no momento em que as duas filosofias parecem coincidir, é necessário também demarcarmos as principais diferenças entre ambas. Enquanto para o Bispo de Hipona a consciência dessa verdade, que ultrapassa o próprio homem (Deus, o soberano bem) é obtida interiormente, através de uma reflexão racional acerca da incompreensibilidade relacionada à noção de número, para Pascal a religião torna-se um autêntico referencial antropológico não porque aponta para o próprio soberano bem, fonte de toda verdade, mas porque desvenda as razões da busca por esse bem maior.

Nesse sentido, há uma grande diferença que aparta o pensador jansenista de Santo Agostinho. Enquanto em Agostinho a via da interioridade é capaz de nos conduzir à constatação da existência de Deus, em Pascal não constatamos a presença da 
subjetividade funcionando como um referencial capaz de nos conduzir a Deus. O viés subjetivo é alheio à construção antropológica de Pascal, justamente porque ele faz a seguinte constatação: pensar em si mesmo é algo desesperador para o homem.

A profunda angústia e a situação desesperadora, que acomete o homem que pensa em si mesmo, nos leva a concluir que o caminho do autoconhecimento, por uma via subjetiva, é uma possibilidade estranha ao caráter desse ser. Segundo Luis Felipe Pondé: “é impossível para o homem estar consigo mesmo porque tal situação leva-o forçosamente ao reconhecimento de uma condição não prazerosa que é interna a ele mesmo" (Pondé 10, p.237). É nesse sentido, que o ser humano de modo geral busca fugir do "desprazeroso" conhecimento de si através de determinados prazeres que o alienarão de si mesmo.

Dessa forma, a questão da busca desenfreada pelo repouso assume em Pascal um aprofundamento maior do que aquele observado no bispo de Hipona. Com efeito, é como se em Agostinho, o homem fosse "naturalmente" apto a desejar a felicidade, enquanto que em Pascal o desejo pela felicidade não fosse jamais considerado como indício da natureza humana, mas resultado de sua corrupção, e assim o "peso" que nos inclina, o centro gravitacional de nosso ser, não é o amor.

Nesse caso, é a perda da natureza que é vivenciada como busca, portanto, a inclinação em direção à felicidade é muito mais o resultado da falta de referenciais do que propriamente da presença destes. A ausência de um ponto fixo, seja nas coisas exteriores, seja na própria subjetividade, leva o ser humano a constituir uma natureza inconstante, marcada pelas "idas e vindas" e pela descontinuidade. Não há unidade de movimento em Pascal, porque o homem não possui um centro gravitacional para conferir sentido e equilíbrio a suas ações.

A natureza do homem se define por sua inconstância e sua descontinuidade; não saberíamos definir o homem pela unidade de um movimento (ordenado, frequentemente pensado como peso) para o qual ele tenderia; Há itus et reditus na natureza humana”. (Carraud 3, p. 295).

Da perspectiva pascaliana, compreender o sentido da existência humana apenas como a busca constante pelo repouso e pela felicidade, sem fazer uma reflexão acerca das razões dessa busca, é ter uma compreensão reduzida e unilateral do homem, já que essa interpretação contempla apenas o lado mais superficial da questão e não passa pela consideração da causa da necessidade de agitação e distração que é parte integrante de 
nós mesmos. A razão desse efeito somente pode ser vislumbrada, quando analisamos a problemática da inconstância do homem, presente no divertimento à luz do único princípio explicativo que permite harmonizar as contradições, o dogma do pecado original. Nesse sentido, dirá Pascal:

Dizer a um homem que viva em repouso é o mesmo que lhe dizer viva feliz; é o mesmo que lhe aconselhar uma condição totalmente feliz e que possa ser examinada à vontade, sem que se encontre nela motivo de aflição; é aconselhar-lhe... Não é, portanto, compreender a natureza (Pascal 9, Pensamento 139).

Desse modo, concordamos com a afirmação de Sellier: o pensamento de Pascal ultrapassa aquele do Bispo de Hipona, no tocante à profunda inconstância observada no ser humano. Inconstância essa que corrói nosso ser, atingindo a própria interioridade, pois "não somente o homem não passa de um joguete em meio aos elementos, mas ele também é fluente, mutável" (Sellier 11, p.33). O próprio homem, e, portanto, a subjetividade é "fluente" e "mutável", não podendo mais ser considerada um referencial seguro em termos morais.

Com Pascal, a temática socrática do "conhece-te a ti mesmo" possui outra conotação. Certamente aqui estamos muito distantes da consideração da alma como sítio da virtude. Para o pensador jansenista, conhecer-se a si mesmo é acima de tudo ter consciência da própria miséria e pequenez que não envolve apenas a insignificância física e cosmológica, presente na temática da desproporção do homem ${ }^{6}$, mas está relacionada ao sentimento de perda da própria dimensão da subjetividade como referencial antropológico.

\section{Conclusão}

A nosso ver o pensamento de Pascal inaugura uma nova fase na questão do autoconhecimento. Com efeito, consideramos que a questão do conhecimento de si permaneça em sua filosofia e seja uma das principais preocupações desse autor, como ele mesmo aponta: "é preciso conhecer-se a si mesmo; se isso não servisse para encontrar a verdade, serviria ao menos para regular a vida, e não há nada mais justo". (Pascal 9, Pensamento 66). Somente que agora essa problemática moral passa por uma nova via: pela ausência de referenciais calcados na subjetividade, quando se trata de fazer uma reflexão acerca do homem. 
Podemos nos arriscar a dizer que, nesse caso, o conhecimento antropológico está mais próximo da hermenêutica do que da metafísica. Com efeito, a temática do autoconhecimento em Pascal está mais relacionada com a tentativa de se interpretar as contradições humanas do que propriamente de compreendê-lo dentro de um quadro cosmológico, como intencionava, por exemplo, Santo Agostinho. Nesse sentido, pensadores como Pascal inauguram uma nova via na questão do "nosce teipsum" (conhece-te a ti mesmo), é o que aponta o filósofo Étienne Gilson:

Fundando assim a moral no conhecimento de si, Pascal permanecia fiel a mais antiga das tradições filosóficas, porém a maneira como ele interpretava esse conhecimento era nova, e a história não compreenderia como se efetuou a transição de Sócrates a Pascal sem reservar um capítulo importante ao Nosce teipsum dos filósofos cristãos (Gilson 5, p.279).

Segundo Gilson, entre Sócrates (o inaugurador da ideia de interioridade na filosofia ocidental) e Pascal há uma transformação operada de modo radical. Entre os dois podemos colocar um momento de transição, o pensamento dos filósofos cristãos e notadamente o de Agostinho, responsável por resgatar a noção de interioridade, como a dimensão que possibilita um encaminhamento rumo a um referencial transcendente.

Desse modo, mesmo que Pascal possa ser considerado autor cristão, devemos atentar para essa grande diferença entre o seu pensamento e o do bispo de Hipona. A religião nas mãos de Pascal deve ser considerada não como aquela que possibilita uma visão dogmática acerca da natureza humana e do seu lugar dentro do cosmos, mas como um instrumento que possibilita decifrar e harmonizar as contrariedades existentes no homem, compreendendo segundo a mesma perspectiva (pecado original), a inclinação para o movimento e o desejo pelo repouso presentes na questão da busca pelo soberano bem.

\section{REFERÊNCIAS BIBLIOGRÁFICAS:}

1. AGOSTINHO. Confissões. Coleção Os Pensadores. São Paulo, Nova Cultural,1999. 2. . O Livre-Arbítrio. São Paulo, Paulus, 2008.

3. CARRAUD, V. Pascal et La Philosophie. Paris, Presses Universitaires de France, 2007.

4. GILSON, É. Introdução ao Estudo de Santo Agostinho. São Paulo, Paulus-Discurso Editorial, 2007. 
5 . O Espírito da Filosofia Medieval. São Paulo, Martins Fontes, 2006.

6. LAPORTE, J. «Pascal et La Doctrine de Port-Royal » in Études Sur Pascal, Colin, Paris, 1923.

7. MAGNARD, P. Pascal ou l'art de La Digression. Paris, Ellipses, 1997.

8. NOVAES, M. A Razão em Exercício, Estudos Sobre a Filosofia de Agostinho. São Paulo, Paulus-Discurso Editorial, 2007.

9.PASCAL, B. Pensamentos, Edição Brunschvicg. Tradução de Sérgio Milliet. São Paulo, Difusão Européia do Livro, 1961.

10. PONDÉ, L. F. O Homem Insuficiente, Comentários de Antropologia Pascaliana. São Paulo, Edusp, 2001.

11. SELLIER, P. Pascal et Saint Augustin. Paris, Albin Michel, 1995.

THE INTERIORITY AND THE QUESTION OF SOVEREIGN RIGHT IN PASCAL

\begin{abstract}
This paper attempts to elucidate in what consists the issue of self-knowledge in Blaise Pascal. In our view, this question is strictly related to the theme of searching for the supreme good, that is present in his "Pensées", more specifically in the fragments related to the "Divertissement". In these fragments the French thinker works with the idea of misery in man, as a form of a sort of emptiness. The nature of man, being emptied of all meaning, makes him search for distractions and occupations in a way to make him happy. In this sense, knowing himself, according to Pascal, is recognizing his own misery in the context of the phenomenon of joy. Furthermore, we intend to make a comparison between the way of thinking of Pascal and St. Augustine, regarding to the issue of interiority and the search for superior good, to show how Pascal's anthropological reflections on these issues go beyond the thought of the bishop of Hippo.
\end{abstract}

Keywords: anthropology, moral, self- knowledge, subjectivity, affliction

\title{
NOTAS
}

\footnotetext{
${ }^{1}$ É preciso frisar que o âmbito relacionado ao coração cumpre três funções em Pascal: em sentido epistemológico, o coração cumpre a função de fundamentar o conhecimento, fornecendo a evidência acerca dos primeiros princípios, enquanto que em âmbito moral, em que é chamado de "esprit de finesse", cumpre o papel de fornecer determinadas regras para o nosso agir. Já em sentido religioso ele desempenharia a função de estabelecer o contato do homem com Deus, sendo considerado o órgão da fé. Sobre a definição e o papel desempenhado pelo coração em Pascal, ver Sellier 11, p. 117-139. Para uma melhor compreensão da temática epistemológica em Pascal e da função que o âmbito do coração ocupa em sua teoria do conhecimento ver nosso artigo, publicado nos cadernos espinosanos XXIV, intitulado "Pascal e a Questão dos Limites do Conhecimento".

${ }^{2}$ Carraud 3, p. 317-318.
} 


\begin{abstract}
${ }^{3}$ Alguns comentadores de Pascal como Pierre Magnard e Philippe Sellier defendem a ideia de que o coração seria o órgão da interioridade, pois, tal como em Agostinho, reenvia o homem a certo contato com Deus. Concordamos com esses autores, embora achemos que essa concepção não invalide a nossa tese da presença de uma subjetividade esvaziada de referenciais antropológicos. Pelo contrário, até a corrobora. Com efeito, tal vazio também pode ser percebido de forma afetiva, por meio do próprio coração (o sentimento do tédio). Nesse sentido dirá Pascal, "o tédio, por sua autoridade privada, não deixaria de sair do fundo do coração, onde tem raízes naturais, e de nos encher o espírito com o seu veneno". (Pascal 9, Pensamento 139). O próprio Pierre Magnard concebe o coração como "o órgão espiritual por excelência, vítima do vazio, quando Deus não se manifesta, procurando preencher esse vazio pelo "divertimento" e "tender ao repouso pela agitação". (Magnard 7, p.21). Na opinião de Magnard, portanto, mesmo que o coração seja um dos elementos principais que constituem a interioridade do homem, ele também está à mercê do nada, podendo ser vitimado pelo vazio existencial.
\end{abstract}

4 “Nossa natureza está no movimento, o inteiro repouso é a morte”. (Pascal 9, Pensamento 129).

${ }^{5}$ É exatamente essa a tese central defendida por Pierre Magnard. Para ele, Pascal vai utilizar "esse ponto de vista superior que Ihe fornece a fé cristã, para decifrar o livro da Criação. Galileu, Descartes não cessaram de repetir que o mundo era um "criptograma", do qual basta compreender que é escrito em caracteres matemáticos para decifrá-lo. O problema é mais complexo para Pascal, para ele se trata não do livro do mundo, mas do livro do homem." (Magnard 7, p.19).

6 "Afinal, que é o homem dentro da natureza? Nada em relação ao infinito; tudo em relação ao nada; um ponto intermediário entre tudo e nada. Infinitamente incapaz de compreender os extremos, tanto o fim das coisas como o seu princípio permanecem ocultos num segredo impenetrável". (Pascal 9, Pensamento 72). 